\title{
FILOSOFI HUMA BETANG SUKU DAYAK NGAJU SEBAGAI UPAYA PEMBINAAN GEREJA SECARA KONTEKSTUAL BERDASARKAN KISAH PARA RASUL 2:42-47
}

\author{
Sabda Budiman $^{1}$, Yelicia ${ }^{2}$, Maria Lidya Wenas ${ }^{3}$ \\ ${ }^{1,2,3}$ Sekolah Tinggi Teologi Simpson Ungaran \\ 1 sabdashow99@gmail.com, ${ }^{2}$ yeliciapky@gmail.com, ${ }^{3}$ liliwenas@yahoo.com
}

\begin{abstract}
Abstrak
Suku Dayak Ngaju merupakan suku yang berada di Kalimantan Tengah yang memiliki filosofi unik dari Huma Betang yang dimilikinya. Sebagai warga Dayak Ngaju, tentu mengetahui nilai filosofi dari Huma Betang. Meninjau filosofi Huma Betang tersebut secara alkitabiah, didapati ada keselarasan dengan gaya hidup jemaat mula-mula yang dijelaskan dalam Kisah Para Rasul 2:42-47. Dengan demikian, yang menjadi rumusan masalah dalam penelitian ini ialah bagaimana kontekstualisasi pembinaan umat mengenai fungsi gereja berdasarkan Kisah Para Rasul 2:42-47 melalui filosofi Huma Betang suku Dayak Ngaju? Penulis menggunakan metode kualitatif dengan pendekatan deskriptif dalam penelitian ini. Data seperti literatur-literatur serta penelitian-penelitian yang berkaitan dengan topik ini diamati dan diolah guna menemukan informasi yang tepat. Kemudian penulis memaparkan hasil penelitian secara sistematis. Adapun hasil dari penelitian ini ialah filosofi Huma Betang yaitu nilai kebersamaan, nilai kejujuran, nilai kesetaraan, dan nilai kekeluargaan secara berurutan dikontekstualisasikan sebagai persekutuan, integritas diri, kasih terhadap sesama, dan sebagai anggota tubuh Kristus. Kesimpulannya ialah upaya kontekstualisasi filosofi Huma Betang menjadi rujukan yang baik dalam melakukan pembinaan gereja dalam suku Dayak Ngaju.
\end{abstract}

Kata Kunci : Huma Betang; Dayak Ngaju; filosofi; kontekstual; jemaat mula-mula

\begin{abstract}
Abstarct
Dayak Ngaju tribe is a tribe located in Central Kalimantan that has a unique philosophy of Huma Betang. As a dayak ngaju, certainly know the philosophical value of Huma Betang. Reviewing Huma Betang's philosophy biblically, it is found that there is harmony with the lifestyle of the early church described in Acts 2:42-47. Thus, the formulation of the problem in this study is how contextualize the formation of the people on the function of the church based on Acts 2:42-47 through the philosophy of Huma Betang Dayak Ngaju tribe? The authors used qualitative methods with descriptive approaches in this study. Data such as literature and research related to this topic are observed and processed in order to find the right information. Then the authors presented the results of the study systematically. The result of this study is Huma Betang's philosophy of mutual value, honesty value, equality value, and family values sequentially contextualized as fellowship, self-integrity, love for others, and as a member of the body of Christ. The conclusion is that the contextualization efforts of Huma Betang philosophy become a good reference in the construction of the church in the Dayak Ngaju tribe.
\end{abstract}

Keywords: Huma Betang; Dayak Ngaju; philosophy; contextual; the early church 


\section{PENDAHULUAN}

Dalam keberagaman suku dan budaya di Indonesia khususnya di suku Dayak Ngaju Kalimantan Tengah yang memiliki keunikan tersendiri berdasarkan adat istiadat yang diwariskan oleh nenek moyang yaitu berupa rumah adat Betang. Riwut mengatakan bahwa kata Dayak itu sendiri menurut pendapat banyak orang berarti Orang Gunung. Akan tetapi pengertian Dayak berkemungkinan ialah orang yang tinggal di gunung. Hal itu dikarenakan alasan bahwa suku dayak mayoritas tinggal di udik-udik sungai yang berada di gunung-gunung atau dataran tinggi. ${ }^{1}$ Terlepas dari itu, suku Dayak diam di pulau Kalimantan. Seluruh daerah di pulau Kalimantan dihuni oleh orang Dayak.

Suku Dayak Ngaju adalah suku Dayak yang tinggal di Kalimantan Tengah. Sebagai masyarakat suku Dayak Ngaju Kalimantan Tengah tentu bangga memiliki rumah adat Betang (Huma Betang) dalam bahasa Dayak Ngaju. Di dalam berdirinya Huma Betang tentu tidak lepas daripada gotong royong atau kerjasama yang tinggi hasil dari para leluhur atau nenek moyang dan Huma Betang yang dibangun berukuran besar dengan panjang mencapai 30-150 meter, lebarnya antara 10-30 meter dan tinggi antara 3-4 meter dari tanah. ${ }^{2}$ Huma Betang dapat dihuni 100-200 jiwa dan dikepalai oleh kepala suku didalamnya, selain itu masyarakat Dayak Ngaju juga memiliki keberagaman mulai dari agama,

${ }^{1}$ Tjilik Riwut, Kalimantan Membangun Alam Dan Kebudayaan (Yogyakarta: NR Publishing, 2007), p. 261-265.

${ }^{2}$ Chris Apandie and Endang Danial Ar, "Huma Betang: Identitas Moral Kultural Suku Dayak Ngaju Kalimantan Tengah," Journal Of Moraland Civic Education Vol. 3, No. 2 (2019): p. 79. suku dan bahasa yang ada, akan tetapi sebagai masyarakat dayak penduduk asli sangat menjaga persatuan yang tinggi khsusnya dalam toleransi antar kepercayaan. $^{3}$

Indonesia mengakui adat daripada suku dayak Kalimantan Tengah yaitu Huma Betang yang memiliki filosofi (filosofis) yang berlaku baik secara sosiologis maupun secara yuridis di masyarakat dengan adanya peraturan daerah provinsi Kalimantan Tengah Nomor 10 Tahun 2010 mengenai perubahan peraturan daerah provinsi Kalimantan Tengah No 16 Tahun 2008 tentang kelembagaan adat dayak di Kalimantan Tengah yang berlaku berdasarkan pengalaman hidup yang membentuk norma atau aturan perilaku dengan filosofi Huma Betang. Huma Betang merupakan suatu rumah adat yang khas dimiliki oleh suku dayak, secara khusus Dayak Ngaju. Model dari Huma Betang ini ialah menyerupai rumah panggung yang berbentuk tinggi dan panjang. Secara umum, tinggi daripada Huma Betang tersebut ialah kisaran tiga hingga lima meter dan panjangnya sekitar 150 meter dan lebarnya 30 meter. $^{4}$

Di tengah keberagaman suku dan budaya serta kepercayaan dalam Suku Dayak Ngaju Kalimantan Tengah yang bangga memiliki rumah adat Betang, yang mana terdapat filosofi yang kuat yang terkandung dalam Huma Betang yang masih dipegang oleh masyarakat suku Dayak Ngaju saat ini. Hal ini merupakan suatu

\footnotetext{
${ }^{3}$ Ibid.

${ }^{4}$ Ibnu Elmi AS Pelu and Jefry Tarantang, "Interkoneksi Nilai-Nilai 'Huma Betang' Kalimantan Tengah Dengan Pancasila," Jurnal Studi Agama dan Masyarakat 14, no. 2 (December 2018): p. 120.
} 
kesempatan bagi orang percaya untuk dapat membina umat Tuhan yang tinggal atau menetap di Kalimantan Tengah khususnya suku Dayak Ngaju untuk dapat menyampaikan kasih Allah agar dapat bertumbuh dan menjadi orang percaya yang memiliki gaya hidup sebagaimana jemaat mula-mula. Pembinaan yang dimaksud adalah suatu tugas dan tanggung jawab pendeta, penginjil dan orang yang telah percaya untuk dapat membina orang lain di dalam ajaran iman Kristen yaitu kepada Tuhan Yesus Kristus. Secara sederhananya, di dalam suatu lembaga keluarga kecil yang terdiri dari ayah, ibu dan anak-anak dilakukan pembinaan rohani secara berkesinambungan untuk mengajarkan serta menanamkan nilai-nilai Kristiani guna mencapai suatu perubahan ke arah yang baik oleh kuasa Roh Kudus sehingga anggota keluarga dididik sesuai dengan kehendak Allah yang berpedoman pada firman-Nya. ${ }^{5}$

Dalam artikel ini, penulis mengkaji filosofi yang terkandung dalam Hита Betang yang kemudian dijadikan sebagai media kontekstualisasi untuk membina masyarakat Dayak Ngaju dalam memahami fungsi gereja yang sebenarnya. Oleh karena itu pembinaan sangat perlu dilakukan bagi orang percaya yang dimulai dari diri sendiri atau dalam suatu keluarga kecil dan kemudian dilakukan kepada orang lain supaya menghasilkan buah sesuai dengan apa yang dikehendaki Allah dalam hidup umat-Nya. Berdasarkan latar belakang tersebut, penulis merumuskan masalah

\footnotetext{
${ }^{5}$ Santy Sahartian, "Pengaruh Pembinaan Rohani Di Keluarga Terhadap Karakter Pemuda Berdasarkan Kolose 2:6-10," Jurnal Teologi Sistematika Dan Praktika Vol. 2, No 1 (June 2019): p. 25.
}

sebagai berikut: Filosofi apa yang terkandung di dalam Huma Betang Dayak Ngaju? Bagaimana kontekstualisasi pembinaan umat mengenai fungsi gereja berdasarkan Kisah Para Rasul 2:42-47 melalui filosofi Huma Betang suku Dayak Ngaju? Tujuan dari penulisan ini ialah untuk memaparkan filosofi yang terkandung di dalam Huma Betang suku Dayak Ngaju dan menemukan kontekstualisasi yang tepat untuk pembinaan umat mengenai fungsi gereja berdasarkan Kisah Para Rasul 2:42-47 melalui filosofi Huma Betang suku Dayak Ngaju.

\section{METODE PENELITIAN}

Dalam penelitian ini, penulis menggunakan metode penelitian kualitatif. Alasan memilih metode ini ialah karena metode penelitian kualitatif lebih menekankan makna dari penelitian yang dilakukan. ${ }^{6}$ Melalui penelitian ini, penulis hendak menemukan suatu makna yaitu perjumpaan fungsi gereja yang terdapat dalam Kisah Para Rasul 2:42-47 di dalam filosofi Huma Betang suku Dayak Ngaju. Selain itu, penelitian ini juga menggunakan pendekatan deskriptif dalam pengumpulan data. Moleong menjelaskan bahwa setiap data yang diperoleh oleh peneliti dalam pendekatan deskriptif, dapat menjadi kunci terhadap apa yang sedang diteliti. Pendekatan deskriptif juga tidak memandang hal-hal yang diamati memang demikian adanya. ${ }^{7}$ Metode kualitatif dengan

\footnotetext{
${ }^{6}$ Albi Anggito Setiawan Johan, Metodologi penelitian kualitatif (Sukabumi: CV Jejak (Jejak Publisher), 2018), p. 8.

${ }^{7}$ Lexy J. Moleong, Metodologi Penelitian Kualitatif (Bandung: Remaja Rosdakarya, 2018), p. 11.
} 
pendekatan deskriptif penulis anggap cocok karena data-data yang dikumpulkan dapat menjadi kunci dalam penelitian ini. Adapun dalam proses pengumpulan data, penulis mencari literatur-literatur yang terkait dengan topik penelitian seperti buku, jurnal, dan juga situs-situs website. Kemudian penulis mengkaji data yang dikumpulkan serta mengolahnya dan kemudian disajikan secara sistematis.

\section{BATASAN PENELITIAN}

Adapun penelitian ini hanya meninjau filosofi Huma Betang dalam suku Dayak Ngaju. Kemudian upaya pembinaan umat secara kontekstual juga ditujukan kepada orang Kristen dalam suku Dayak Ngaju, secara khusus yang imannya masih "suam-suam kuku". Artinya tidak bertumbuh dan juga tidak mati. Firman Tuhan yang digunakan juga hanya berfokus pada Kisah Para Rasul 2:42-47.

\section{Filosofi Huma Betang Suku Dayak Ngaju}

Filosofi dari Huma Betang ini didasarkan pada tujuh unsur kebudayaan yang terdapat di dalamnya, yaitu; (1) sistem keberagaman religi, nilai, pandangan hidup, komunikasi keagamaan, upacara keagamaan,(2) sistem kemasyarakatan atau organisasi sosial yang terdiri dari kekerabatan, asosiasi dan perkumpulan, sistem kenegaraan, sistem kesatuan hidup, perkumpulan,(3) sistem pengetahuan terdiri dari flora dan fauna, waktu, ruang dan bilangan, tubuh manusia dan perilaku antar sesama,(4) bahasa terdiri dari alat untuk berkomunikasi berbentuk lisan dan tulisan,(5) kesenian yang terdiri dari seni patung/pahat, relief, lukis dan gambar, rias, vokal, musik, bangunan, kesustraan, drama,(6) sistem mata pencaharian/ekonomi terdiri dari berburu, bercocok tanam, peternakan, perikanan, perdagangan,(7) sistem peralatan hidup atau teknologi yang digunakan yang terdiri dari sistem produksi, distribusi, transportasi, komunikasi, konsumsi, pakaian dan perhiasan, rumah dan senjata. ${ }^{8}$ Ketujuh unsur tersebut menjadi dasar dalam membentuk filosofi daripada Huma Betang dalam suku Dayak Ngaju tersebut.

Melalui landasan filosofi daripada Huma Betang di atas tampak bahwa kehidupan masyarakat suku Dayak Ngaju di Kalimantan Tengah senantiasa berpadanan dengan kebudayaan yang telah diwarisakan oleh nenek moyang mereka. Generasi masa kini didorong untuk melestarikan dengan baik ditengah zaman yang semakin maju. Pelestarian tersebut terlihat dari model Huma Betang yang dijadikan modern dengan ukiran yang berciri khas Huma Betang suku Dayak Ngaju dan juga sistem kekeluargaan yang tinggi dijunjung dalam setiap aspek kehidupan daripada masyarakat suku dayak Kalimantan Tengah. Keberadaan Huma Betang di tengah masyarakat suku Dayak Ngaju Kalimantan Tengah sampai saat ini mempunyai filsafaf yang terkandung di dalamnya melalui kehidupan yang sudah menjadi adat dan istiadat daripada nenek moyang suku Dayak Ngaju Kalimantan Tengah. Berdasarkan filosofinya, Huma Betang Kalimantan tengah menjunjung tinggi perdamaian dan anti terhadap kekerasan serta hidup dengan toleransi yang tinggi antar-umat beragama. Lebih spesifiknya nilai-nilai daripada Huma Betang melingkupi empat pilar yaitu

${ }^{8}$ Apandie and Ar, "Huma Betang: Identitas Moral Kultural Suku Dayak Ngaju Kalimantan Tengah," p. 79. 
kebersamaan, kejujuran, kesetaraan, dan kekeluargaan. ${ }^{9}$

\section{Nilai Kebersamaan}

Nilai kebersamaan di dalam masyarakat Dayak Ngaju merupakan nilai utama yang menonjol. Kebersamaan tersebut terlihat dari kehidupan masyarakat Dayak Ngaju yang hidup berbaur tanpa memandang perbedaan-perbedaan yang mereka miliki. Nilai kebersamaan ini tidaklah mudah dibangun. Pelu dan Tarantang mengungkapkan bahwa Huma Betang dihuni oleh beragam manusia dengan beragam kepercayaan. Hal tersebut merupakan hal yang unik. Meskipun demikian, mereka selalu hidup rukun dan perbedaan-perbedaan yang ada tidak dijadikan sebagai alat untuk memecah-belah. ${ }^{10}$ Nilai kebersamaan yang terbentuk dari Huma Betang telah mendarah daging dalam diri masyarakat Dayak Ngaju.

Tentunya nilai kebersamaan ini terbentuk sejak zaman dahulu kala. Namun nilai kerbesamaan ini tetap berlanjut hingga saat ini. Penelitian yang dilakukan oleh Maresty dan Zamroni, didapati bahwa masyarakat di sekitar Huma Betang masih sering berkumpul dan duduk bersama di depan rumah dan juga di pinggir jalan sekitar Huma Betang pada sore hari. Maresty dan Zamroni mengatakan bahwa hidup di tempat yang sama belum tentu dapat menikmati kebersamaan, namun masyarakat Dayak Ngaju berbeda. Di Huma Betang, masyarakat yang tinggal di situ hidup dalam kebersamaan. ${ }^{11}$ Hal menarik yang dikatakan

\footnotetext{
${ }^{9}$ Pelu and Tarantang, "Interkoneksi Nilai-Nilai Huma Betang Kalimantan Tengah Dengan Pancasila,” p.3.

${ }^{10}$ Pelu and Tarantang, "Interkoneksi NilaiNilai 'Huma Betang' Kalimantan Tengah Dengan Pancasila," p.121.

${ }^{11}$ Era Maresty and Zamroni, "Analisis NilaiNilai Budaya Huma Betang Dalam Pembinaan
}

oleh Laksono dkk bahwa Huma Betang bukan hanya sekedar rumah yang sebagai tempat tinggal masyarakat Dayak Ngaju saja, tetapi Huma Betang merupakan jantung dari struktur sosial dalam kehidupan masyarakat Dayak Ngaju. ${ }^{12}$ Terlihat bahwa kebersamaan sangat kuat di dalam masyarakat Dayak Ngaju yang terbentuk melalui Huma Betang tersebut.

Kebersamaan juga terlihat dari pola bekerja masyarakat Dayak Ngaju. Sikap saling bergotong royong yang mulanya terbentuk dari dalam Huma Betang tersebut, kini juga meluas dengan gotong royong di ladang dan dalam pekerjaan lainnya. Masyarakat Dayak Ngaju juga bersamasama membangun daerahnya tanpa memandang agama dan latang belakang dari rekannya sendiri. Hal itu dilakukan dengan setulus hati demi kepentingan bersama. Dalamh hal keamanan juga, masyarakat Dayak Ngaju telah dibentuk agar saling menjaga ketentraman dan kemananan atas kriminalisasi yang mungkin terjadi. Nilai itu semua terbentuk di dalam Huma Betang. ${ }^{13}$

\section{Nilai Kejujuran}

Sebagaimana yang dikatakan oleh Maresty dan Zamroni bahwa di dalam kehidupannya, masyarakat suku Dayak yang tinggal di Huma Betang menekankan nilai kejujuran. Hal tersebut tampak dari sikap mereka seperti tidak semena-mena memakai

Persatuan Kesatuan Bangsa SIswa SMA Di Kalimantan Tengah," Harmoni Sosial: Jurnal Pendidikan IPS 4, no. 1 (March 2017): p. 71.

${ }^{12}$ P.M. dkk. Laksono, Pergulatan Identitas

Dayak Dan Indonesia: Belajar Dari Tjilik Riwut (Yogyakarta: Galangpress, 2006), p. 75.

${ }^{13}$ Suwarno Suwarno, "Budaya Huma Betang

Masyarakat Dayak Kalimantan Tengah Dalam Globalisasi: Telaah Konstruksi Sosial," LINGUA : Jurnal Bahasa, Sastra, dan Pengajarannya 14, no. 1 (January 2017): p. 94. 
barang yang bukan miliknya sendiri. Jika hendak memakai barang milik orang lain, orang itu terlebih dahulu minta izin kepada yang pemilik barang tersebut. Selain itu, dari pengamatan Maresty dan Zamroni juga, terlihat bahwa anak-anak yang mereka teliti, melakukan kegiatan yang dipercayakan kepada mereka dengan jujur. ${ }^{14}$ Terlihat nilai kejujuran dari masyakarat tersebut yang terbentuk salah satunya dari Huma Betang.

Cherrington menungkapkan bahwa kejujuran merupakan sikap yang terlepas dari penipuan dan kecurangan. Orang yang memiliki sikap jujur tidak mengatakan hal yang mereka tahu itu benar dengan mengatakan hal yang lain. ${ }^{15}$ Kejujuran juga merupakan bagian dari keutuhan diri (integritas). Kejujuran berarti tidak ada suatus kebohongan yang terkandung di dalamnya, meskipun hal kecil. Budaya jujur ini sangatlah berarti sebagai pemersatu kehidupan manusia. Ini juga merupakan salah satu kunci pemersatu masyarakat Dayak Ngaju, yaitu hidup dalam kejujuran. Nilai kejujuran ini juga salah satu faktornya ialah didorong dengan adanya sikap tenggang rasa. Kebiasaan umum yang berlaku dalam masyarakat Dayak ialah berkata apa adanya, meskipun itu menyakitkan. Selain itu, peran dari orang tua dalam Huma Betang yang dilihat dan diteladani oleh anak dalam berprilaku jujur telah menumbuhkan tenggang rasa dalam diri masyarakat Dayak Ngaju. Hal inilah yang kemudian mendorong masyarakat

\footnotetext{
${ }^{14}$ Maresty and Zamroni, "Analisis Nilai-

Nilai Budaya Huma Betang Dalam Pembinaan

Persatuan Kesatuan Bangsa SIswa SMA Di

Kalimantan Tengah,” p. 71.

${ }^{15}$ D.J. Cherrington and J.O. Cherrington, Understanding Honesty, 6th ed., vol. 50 (Internal Auditor, n.d.), p. 92.
}

Dayak Ngaju untuk berkata jujur. Jika seseorang berkata bohong, maka terdapat dalam dirinya rasa yang tidak enak yang mengganggunya. Inilah yang disebut dengan tenggang rasa yang muncul dalam diri seseorang.

\section{Nilai Kesetaraan}

Ada satu peribahasa yang dikenal dalam masyarakat untuk menggambarkan nilai kesetaraan yang terbentuk dari Huma Betang yaitu "duduk sama rendah dan berdiri sama tinggi". Dalam kebersamaan masyarakat Dayak Ngaju, telah terbentuk cara pandang kesetaraan antar sesama. Hal itu membuat satu dengan yang lain saling menghargai dan tidak saling merendahkan. Dalam kesetaraan ini, terdapat sikap kesederajatan yang sama. Di dalam menerima hak dan kewajiban di Huma Betang, tidak ada unsur membeda-bedakan satu dengan yang lain. ${ }^{16}$ Di mata hukum yang berlaku dalam masyarakat Dayak Ngaju juga terdapat kesetaraan dan tidak ada perbedaan antara satu dengan yang lain.

Filsafah kesetaraan ini juga mengandung nilai humanis. Artinya bahwa dalam hal bersosial, sikap saling menghormati menjadi bagian yang penting bagi masyarakat Dayak Ngaju. Hal itu juga berlaku bagi setiap agama dan adat budaya yang berlaku di tempat itu. ${ }^{17}$ Tidak hanya bermanfaat untuk mendorong seseorang untuk menghormati orang lain, melalui Huma Betang juga, terdapat nilai kesetaraan

\footnotetext{
${ }^{16}$ Pelu and Tarantang, "Interkoneksi NilaiNilai 'Huma Betang' Kalimantan Tengah Dengan Pancasila," p. 121.

${ }^{17}$ Ni Nyoman Rahmawati, "Implementasi Nilai Keharifan Lokal (Huma Betang) Dalam Interaksi Sosial Masyarakat Dayak Di Kota Palangka Raya," Jurnal Tampung Penyang 17, no. 1 (June 2019): p. 21.
} 
yang mampu untuk mengikat berbagai perbedaan suatu kesamaan dan persatuan dalam suku Dayak. ${ }^{18}$ Dengan adanya kesetaraan antara satu dengan yang lain membuat masyarakat Dayak Ngaju tidak ada tembok dalam bersosial. Hal penting lainnya yang berkaitan dengan kesetaraan ialah masyarakat Dayak Ngaju, melalui Huma Betang ini, tidak mengenal adanya sistem kasta atau diferensial kelas dalam kehidupan sosial. Hal itulah yang menjadi salah satu faktor bahwa suku dayak, khususnya Dayak Ngaju tidak mengenal dan memberlakukan tingkatan-tingkatan kelas di dalam masyarakat. Hingga saat ini, nilai kesetaraan dalam suku Dayak Ngaju masih tetap bertahan, meskipun memang tidak erat dan kuat seperti dahulu kala.

\section{Nilai Kekeluargaan}

Penghuni Huma Betang menganggap semua masyarakat Betang adalah saudara mereka. Oleh karena mereka keluarga, maka perlu dilindungi dan dikasihi. Jika ada kesulitan-kesulitan yang dialami, maka masyarakat Dayak Ngaju akan saling bergotong-royong untuk membantu orang yang kesulitan tersebut. Istilah yang terdapat dalam suku Dayak Ngaju berkaitan dengan kekeluargaan ialah "sama keme, sama mangat, sama susah" merupakan suatu prinsip hidup yang menekankan kebersamaan yang mana susah dan senang sama-sama ditanggung bersama. ${ }^{19}$ Tidak ada sikap mementingkan diri sendiri, melainkan selalu memperhatikan seluruh anggota

\footnotetext{
${ }^{18}$ Chris Apandie and Endang Danial Ar, "Huma Betang: Identitas Moral Kultural Suku Dayak Ngaju Kalimantan Tengah," Journal of Moral and Civic Education 3, no. 2 (November 2019): p. 88.

${ }^{19}$ Suwarno, "BUDAYA HUMA BETANG MASYARAKAT DAYAK KALIMANTAN TENGAH DALAM GLOBALISASI," p. 95.
}

keluarga. Sikap berkorban demi anggota keluarga yang lain menjadi bagian yang tak terlepaskan dalam hidup masyakarat Dayak Ngaju. Filosofi kekeluargaan satu dari berbagai filosofi yang penting sebagai pebentukan manusia Dayak Ngaju.

Filosifi Huma Betang diantaranya; hidup rukun dan damai walau terdapat banyak perbedaan, bergotong royong, menyelesaikan perselisihan dengan damai dan kekeluargaan, menghormati leluhur. ${ }^{20}$ Pada dasarnya, setiap orang tentu ingin hidup tentram dan menikmati suasana kekeluargaan. Itulah yang tampak dari falsafat hidup masyarakat Dayak Ngaju yang terbentuk dari Huma Betang. Jika salah satu masyarakat didapati ada masalah, masyarakat akan berkumpul sebagai satu keluarga dan menyelesaikan masalah tersebut dengan bermusyawarah. Kebiasaan ini juga disebut dengan istilah Hapakat Basara. $^{21}$ Nilai kekeluargaan juga terlihat dari kehidupan rukun yang dijalankan di dalam Huma Betang. ${ }^{22}$ Kerukunan tersebut diimplementasikan oleh masyarakat Dayak Ngaju melalui kegiatan-kegiatan. Contohnya ialah saat ada salah satu anggota keluarga yang meninggal, masyarakat Dayak Ngaju lainnya ikut berkabung selama satu Minggu. Sikap solidaritas dan kesehatian ini terbentuk dalam kebiasaan Huma Betang.

\footnotetext{
${ }^{20}$ Yoyada Chriat D., Deddi Duto H., and Elisabeth Christine Y., "Perancangan Merchandise Sebagai Media Promosi Budaya Khas Dayak Ngaju Kalimantan Tengah," Jurnal DKV Adiwarna, Universitas Kristen Petra 2, no. 13 (2018): 4.

${ }^{21}$ Rahmawati, "Implementasi Nilai Keharifan Lokal (Huma Betang) Dalam Interaksi Sosial Masyarakat Dayak Di Kota Palangka Raya,” p. 25. ${ }^{22}$ Anggia Amanda Lukman, "Pewarisan Nilai Sebagai Pembentuk Kepribadian Berkarakter Melalui Filosofi Huma Betang Suku Dayak Kalimantan," sosietas 8, no. 1 (2018): p. 454.
} 


\section{HASIL DAN PEMBAHASAN}

\section{Upaya Pembinaan Umat Secara Kontekstual}

Pembinaan dalam konteks ini berbicara tentang pembinaan rohani. Secara umum pembinaan bertujuan untuk membimbing seseorang agar bertumbuh, dalam hal ini bertumbuh dalam iman kepada Yesus Kristus. Pembinaan rohani tersebut dilakukan oleh orang percaya yang telah dewasa secara rohani. Tugas ini tidak hanya dilakukan oleh pendeta atau orang yang berlatar belakang sekolah teologi, melainkan semua orang percaya wajib dan bertanggung jawab untuk membina sesamanya agar bertumbuh dalam pengenalan yang benar akan Allah. Scoot menjelaskan bahwa pembinaan rohani ini berfungsi untuk memperlengkapi seseorang agar bertumbuh di dalam Kristus. ${ }^{23}$ Kemudian Ruth Selan secara konseptual menjelaskan bahwa pembinaan ialah suatu usaha untuk memperlengkapi orang percaya sebagai anggota tubuh Kristus agar memperoleh pengetahuan dan juga keterampilan dalam pelayanan. ${ }^{24}$ Penjelasan-penjelasan yang dipaparkan tersebut menunjukkan bahwa pembinaan dilakukan sebagai upaya memberikan pertumbuhan iman dan juga memperlengkapi untuk memperlengkapi.

Sedangkan kata kontekstual secara umum berarti peyesuaian dengan konteks atau ruang lingkup tertentu dan jikalau dikaitkan dengan teologi yang berkaitan dengan kontekstualisasi teologi yang dikaitkan menurut Bevans adalah suatu

\footnotetext{
${ }^{23}$ Morton Scoot, Pemuridan untuk Semua Orang (Surakarta: Literatur Perkantas, 2011).

${ }^{24}$ Ruth F. Selan, Pedoman Pembinaan Jemaat (Bandung: Kalam Hidup, 2006), p. 22.
}

upaya untuk memahami iman Kristen yang dipandang dari segi suatu konteks tertentu ${ }^{25}$ dan menurut Moreau kekristenan dituntut untuk dapat menyesuaikan diri dengan baik dari segi bentuk, isi dan praksis iman terhadap berbagai latar belakang budaya lain. ${ }^{26}$ Yakob Tomatala menjelaskan bahwa kontekstual ialah berhubungan dengan konteks atau pun penyesuaian dengan konteks tempat dan kebiasaan setempat. Istilah kontekstual telah digunakan secara populer dalam dunia teologi pada akhir abad ke-20. Kata ini ditambahkan pada perbendaharaan kata dalam bidang misi dan teologi sejak diperkenankan oleh Theological Education Fund (TEF) pada tahun 1972. Ada kelompok yang mempergunakan dan mempertahankan penggunaan istilah kontekstualisasi. ${ }^{27}$ Kemudian Yusuf juga memberikan definisi dari kata "kontekstual" sebagai suatu pendekatan yang dilakukan untuk memahami suatu objek dengan melihat faktor eksternal yang mempengaruhi atau membentuk objek. $^{28}$ Hal senada yang dikatakan oleh Kadir bahwa kontekstual ialah situasi yang berhubungan atau berkaitan dengan suatu peristiwa maupun kejadian. $^{29}$ Jadi kontekstual menekankan

\footnotetext{
${ }^{25}$ Robi Panggarra and Leonard Sumule, "Pengaruh Pelayanan Pemuda Berbasis Kontekstual Terhadap Pertumbuhan Gereja Kemah Injil Indonesia Di Kota Samarinda," Jurnal Jaffray Vol. 17, No 1 (April 2019): p. 94.

${ }^{26}$ Ibid.

${ }^{27}$ Yakob Tomatala, Yesus Kristus Juruselamat Dunia (Jakarta: YT Leadership Foundations, 2004), p. 17.

${ }^{28}$ Muhammad Yusuf, Relasi Teks Dan Konteks (Yogyakarta: Indie Book Corner, 2020), p. 32.

${ }^{29}$ Abdul Kadir, "Konsep Pembelajaran Konseptual Di Sekolah," Dinamika Ilmu 13, no. 1 (June 2013): p. 25.
} 
suatu penyesuaian konteks tertentu, baik itu budaya, gaya hidup, dan bahkan suasana. Akan tetapi, subjek yang berkontekstual tidak berubah dengan objek yang dikontekstualisasikan. Namun hanya menjadi serupa agar objek dapat memahami tujuan dan maksud dari subjek.

Dari penjelasan-penjelasan mengenai pembinaan dan juga kontekstual di atas, dapat disimpulkan bahwa pembinaan kontekstual ialah suatu upaya membina individu atau pun kelompok agar dapat bertumbuh dalam Kristus dan memperlengkapinya dengan cara yang relevan dan dimengerti oleh objek yang dilayani, namun dengan prinsip dan dasar yang tidak berubah, yaitu firman Tuhan. Pembinaan yang dilakukan selalu didasarkan pada Alkitab, namun dalam menjelaskannya, menggunakan simbol atau bahasa atau media yang memang relevan dan dipahami oleh kelompok yang dilayani. Marbun menjelaskan bahwa pembinaan rohani selalu dilandasi oleh Alkitab atau firman Tuhan. Alasannya ialah karena pemahaman akan hal-hal rohani tidak didapat dalam buku manapun dan juga berita di dalam Alkitab sangat relevan dan tepat untuk digunakan dalam pembinaan. ${ }^{30}$ Pembinaan umat secara kontekstual perlu dilakukan sebagai model pembinaan yang diharapkan mudah diterima oleh pihak yang dilayani.

Mengamati filsafah yang terdapat dalam Huma Betang pada suku Dayak Ngaju tampak serupa dengan gaya hidup jemaat mula-mula yang dipaparkan dalam Kisah Para Rasul 2:42-27. Dengan meninjau

\footnotetext{
${ }^{30}$ Purim Marbun, "Strategi Dan Model Pembinaan Rohani Untuk Pendewasaan Iman Jemaat," Jurnal Ilmiah Religiosity Entity Humanity (JIREH) 2, no. 2 (December 23, 2020): 154.
}

sumber-sumber yang membahas tentang topik filosofi Huma Betang serta penelitanpenelitan yang terbaru, penulis menemukan sesuatu yang menarik untuk digunakan sebagai upaya pembinaan secara kontekstual dalam suku Dayak Ngaju. Filsafah Huma Betang yang menekankan nilai kebersamaan, nilai kejujuran, nilai kesetaraan, dan nilai kekeluargaan tampak selaras dengan kehidupan jemaat mula-mula. Dengan demikian maka penulis memberikan suatu usul pembinaan umat dalam suku Dayak Ngaju yang telah percaya namun masih "suam-suam kuku" agar dapat kembali kepada esensi gereja yang sesungguhnya. Berikut penjelasan mengenai upaya pembinaan kontekstual melalui filosofi Huma Betang pada suku Dayak Ngaju.

\section{Nilai Kebersamaan Sebagai Persekutuan} (Kis. 2:42, 44)

Nilai kebersamaan yang terdapat di dalam filosofi Huma Betang suku Dayak Ngaju menekankan kebersamaan tanpa memandang perbedaan serta saling bergotong-royong dapat digunakan untuk membangun suatu persekutuan yang intim dalam hal rohani. Kebersamaan dalam suku Dayak Ngaju terlihat serupa dengan apa yang dilakukan oleh jemaat mula-mula. Dalam Kisah Para Rasul 2:42 mengatakan bahwa "Mereka bertekun dalam pengajaran rasul-rasul dan dalam persekutuan. Dan mereka selalu berkumpul untuk memecahkan roti dan berdoa." Kata persekutuan dan selalu berkumpul di dalam ayat tersebut menunjukkan adanya kebersamaan di antara mereka. Witness mengungkapkan bahwa kata persekutuan yang digunakan dalam Kisah Para Rasul 2:42 menunjukkan adanya penanggalan sikap mementingkan diri sendiri dan bersatu 
dengan orang lain demi satu tujuan bersama. $^{31}$ Diketahui bahwa dalam bagian sebelumnya dijelaskan bahwa peristiwa pentakosta, terdapat berbagai macam orang di dalamnya (Kis. 2:8-11) Namun mereka tetap bersama dan bersekutu memuliakan Tuhan. Barclay menjelaskan bahwa jemaat mula-mula ini menunjukkan kualitas terbaik dalam hal kebersamaan. Gereja baru merupakan gereja yang memiliki suatu ikatan. $^{32}$ Brink juga mengatakan bahwa terlihat dari kehidupan jemaat mula-mula yang dijelaskan dalam Kisah Para Rasul 2:42-42 tentang gaya hidup yang saling melayani dan menolong satu sama lain. ${ }^{33}$

Di zaman yang telah maju saat ini, orang-orang tentu akan lebih memenitngkan diri sendiri. Yesus juga memperingatkan hal yang sama bahwa di zaman-zaman yang akhir, kasih kebanyakan orang akan menjadi dingin (Matius 24:12). Tidak menutup kemungkinan juga, kemajuan-kemajuan dan kenyamanan hidup yang dirasakan, secara khusus dalam suku Dayak Ngaju, membuat mereka berada dalam zona nyaman dan kurang memperhatikan kepentingan bersama. Melalui filosofi Huma Betang yang sebagai warisan nilai hidup suku Dayak Ngaju, dapat dikontekstualisasikan untuk menekankan kebersamaan, namun dalam hal-hal rohani, yaitu bersekutu bersama. Persekutuan tidak hanya sebatas berkumpul memuji Tuhan, tetapi juga saling memberi pertolongan jika ada saudara seiman yang

\footnotetext{
${ }^{31}$ Witness Lee, Pelajaran-Hayat Kisah Para Rasul (Yayasan Perpustakaan Injil Indonesia (Yasperin), 2020), Berita 12.

${ }^{32}$ William Barclay, Pemahaman Alkitab Setiap Hari: Kitab Kisah Para Rasul (Jakarta: BPK Gunung Mulia, 2007), p. 43.

${ }^{33}$ H.v.d. Brink, Tafsiran Alkitab Kisah Para Rasul (Jakarta: BPK Gunung Mulia, 2008), p. 46.
}

kekurangan. Sebagaimana yang dilakukan oleh jemaat mula-mula bahwa kesatuan dan kebersamaan mereka diwujudkan dengan membagi-bagikan harta milik mereka sesuai kebutuhan masing-masing. ${ }^{34}$ Pembagian harta tentu tidak atas unsur paksaan sebagaimana sikap dari jemaat mula-mula yang memberi tanpa ada paksaan. ${ }^{35}$ Filosofi Huma Betang yang menekankan nilai kebersamaan sebagai wujud solidaritas, kini digunakan sebagai pembinaan umat untuk kemuliaan Tuhan dan membangun sesama agar bertumbuh dalam pengenalan yang benar akan Allah sehingga orang percaya dalam suku Dayak Ngaju yang masih hidup dalam dosa dapat ditegur dan berubah serta bertumbuh bersama.

\section{Nilai Kejujuran Sebagai Integritas Diri}

(Kis. 2:45)

Nilai kejujuran yang terkandung dalam Huma Betang menekankan kepada karakter individu. Karakter sangat penting dalam setiap kehidupan manusia, secara khusus kejujuran. Suku Dayak Ngaju menghargai kejujuran sebagai sikap yang sopan dan sebagai wujud menghargai sesama. Kejujuran yang ditekankan dimaksudkan agar tidak merugikan orang lain. Nilai ini kemudian penulis tangkap guna memberikan pembinaan rohani kepada masyarakat Dayak Ngaju yang mana perlunya integritas, tetapi bukan integritas di hadapan manusia dengan standar budaya, melainkan firman Tuhan yang menjadi standar dan dasarnya. Nilai kejujuran tersebut kemudian digunakan untuk

\footnotetext{
${ }^{34}$ Sandy Lane West, Handbook To The Bible (Bandung: Kalam Hidup, 2015), p. 621.

${ }^{35}$ Donald A. Carson et al., Tafsiran Alkitab Abad Ke-21 Jilid 3: Matius-Wahyu (Jakarta: Yayasan Komunikasi Bina Kasih, 2017), p. 263.
} 
menekankan pembinaan rohani terhadap pembentukan karakter integritas diri. Integritas ialah sikap diri yang utuh, apa yang ada di dalam hatinya, itulah yang diungkapkan dan dilakukan. Sukama mengatakan bahwa seseorang yang memiliki integritas tentu tidak akan berpura-pura atau bersikap munafik dan ia tidak akan taku terhadap apapun. ${ }^{36}$ Keefauver juga mengatakan bahwa integritas adalah apa yang seseorang lakukan dalam pelayanan pada saat kamera dan mikrofon dimatikan. ${ }^{37}$ Dari penjelasan-penjelasan tersebut dapat disimpulkan bahwa integritas ialah suatu sikap kejujuran baik dari perkataan dan tindakan.

Gereja mula-mula menunjukkan sikap integritas antar sesama. Hal tersebut ditunjukkan melalui harta yang dimiliki merupakan kepunyaan bersama. Di ayat yang ke-45 pada pasal 2 diceritakan bahwa mereka menjual harta miliknya dan membagikannya sesuai kebutuhan masingmasing. Gereja mula-mula telah menunjukkan integritasnya. Bayangkan jika tidak adanya integritas dalam gereja mulamula dalam memberi, barangkali semua nasib dari jemaat mula-mula akan seperti Ananias dan Safira (Kis. 5:1-11). Hal tersebut juga dijelaskan oleh Rumbi bahwa jemaat mula-mula tentu mengalami konflik batin dan punya kecenderungan untuk menyembunyikan hasil jualan harta milik

\footnotetext{
${ }^{36}$ Sukarna Sukarna, "Integritas Seorang Pendidik," JURNAL TEOLOGI GRACIA DEO 1, no. 1 (December 2018): 16, accessed February 23, 2021 , http://e-

journal.sttbaptisjkt.ac.id/index.php/graciadeo/article/v iew/18.

${ }^{37}$ Larry Keefauver, 77 Kebenaran Yang Hakiki Dalam Pelayanan (Semarang: Media Injil Kerajaan, n.d.), p. 121.
}

secara diam-diam. Namun, tidak menutup kemungkinan saat itu, hasil dari penjualan harta milik diserahkan semuanya kepada para rasul. ${ }^{38}$ Integritas yang dimiliki oleh jemaat mula-mula sangat terbukti. Oleh karena itu, nilai kejujuran dari filosofi Huma Betang dapat dikontekstualisasikan untuk membina orang percaya dalam suku Dayak Ngaju untuk menerapkan gaya hidup jemaat mula-mula pada masa sekarang ini.

\section{Nilai Kesetaraan Sebagai Kasih Terhadap} Sesama (Kis. 2: 45b, 46)

Nilai kesetaraan dalam filosofi Huma Betang suku Dayak Ngaju menunjukkan adanya sikap saling menghormati sesama. Huma Betang telah membentuk kehidupan sosial masyarakat Dayak Ngaju yang kemudian membuat masyarakat dari suku Dayak Ngaju tidak memberlakukan tingkatan-tingkatan sosial masyarakat atau kasta-kasta. Meskipun berbeda latar belakang keluarga dan pola pikir, masyarakat suku Dayak Ngaju menekankan adanya kesetaraan satu dengan lainnya. Perilaku tersebut juga selaras dengan sikap dari jemaat mula-mula yang mana mereka berasal dari suku dan bahasa yang berbeda, namun mereka tetap bersama-sama dan bersatu hati. Dari sikap kesetaraan tersebut yang akhirnya mendorong mereka untuk dapat menghormati dan menolong sesama. Kasih yang ditunjukkan oleh jemaat mulamula tentunya diawali dengan sikap saling menerima dan menghargai satu sama lain sebagai makhluk ciptaan yang sederajat.

Dalam artikelnya, Tembay dan Harefa menjelaskan bahwa kesatuan

\footnotetext{
${ }^{38}$ Frans Paillin Rumbi, "Manajemen Konflik Dalam Gereja Mula-Mula: Tafsir Kisah Para Rasul 2:41-47" (n.d.): 15, accessed February 23, 2021, https://core.ac.uk/reader/231150420.
} 
sebagaimana yang dilakukan oleh jemaat mula-mula menjelaskan bahwa tidak adanya perbedaan di antara mereka. Tidak ada konsep tentang tuan dan budak, orang kaya dan orang miskin, di dalam jemaat tersebut. Semuanya setara dan sehati untuk berkumpul bersama menyembah Tuhan dan membantu saudara-saudara yang berkekurangan. Tidak ada orang Yahudi dan non-Yahudi, tidak ada konflik antar suku dan budaya, semuanya setara dan saling menunjukkan kasih terhadap sesama. ${ }^{39}$ Whitney juga mengatakan bahwa perilaku suka menolong dan berbagi merupakan karakter dari orang yang telah lahir baru. Saling memperhatikan dan saling mengasihi merupakan cara untuk merefleksikan diri sebagai pengikut Kristus. ${ }^{40}$ Aktivitas makan bersama menunjukkan bahwa implementasi kasih di antara jemaat mula-mula saat itu. Paradigma yang telah terbentuk dari pribadi suku Dayak Ngaju mengenai kesetaraan ini dapat digunakan sebagai dasar paradigma dalam mengajarkan kasih terhadap sesama.

\section{Nilai Kekeluargaan Sebagai Tubuh Kristus} (Kis. 2:44, 46)

Sebagaimana slogan yang dimiliki oleh suku Dayak Ngaju yaitu "sama keme, sama mangat, sama susah" yang berarti susah dan senang sama-sama ditanggung bersama dapat dikontekstualisasikan sebagai prinsip dasar menjadi orang Kristen yang sejati. Modal awal dari prinsip hidup orang Dayak Ngaju ini dapat digunakan sebagai

\footnotetext{
${ }^{39}$ Aris Elisa Tembay and Febriaman Lalaziduhu Harefa, "Gerakan Perintisan Jemaat Dalam Kisah Para Rasul Bagi Pengembangan Gereja Masa Kini," SCRIPTA: Jurnal Teologi dan

Pelayanan Kontekstual 3, no. 1 (2017): p. 28.

${ }^{40}$ Donald S. Whitney, Spiritual Check Up10 Pertanyaan Untuk Memeriksa Kesehatan Rohani Anda (Yogyakarta: Yayasan Gloria, 2011), p. 80.
}

dasar untuk menanamkan kesatuan tubuh Kristus. Sebagai tubuh Kristus, perhatian terhadap sesama sangat penting. Jika bagian anggota tubuh merasa sakit, maka bagian tubuh lain turut merasakannya. Selain itu, jika bagian tubuh yang satu berkekurangan, maka anggota tubuh yang lain turut memberi perhatian dan menolong. Namun perlu diperhatikan bahwa konsep hidup di dalam jemaat mula-mula bukanlah sebagaimana konsep pandangan komunis yang sama rasa, sama rata. Lotnatigor Shihombing menjelaskan bahwa gereja yang mula-mula tetap memiliki hak pribadi atau kuasa atas harta bendanya. Namun sebagai anggota tubuh Kristus yang baik, mereka memiliki tanggung jawab untuk membantu anggota yang berkekurangan. ${ }^{41}$ Hak asasi sebagai manusia yang utuh tetap dimiliki oleh jemaat mula-mula. Memberi bukan karena dipaksa namun sebuah kerelaan hati.

Jika kekeluargaan yang dilakukan oleh suku Dayak Ngaju hanya sebagai wujud perhatian dengan bersama menanggung suka maupun duka dan saling membantu, nilai kekeluargaan tersebut dikontekstualisaikan dengan hubungan kekeluargaan di dalam iman kepada Yesus Kristus. Tujuannya tentu agar masyarakat Dayak Ngaju yang berpegang pada filosofi Huma Betang dapat bertumbuh secara iman dan pengetahuan di dalam Kristus dan tentunya tetap saling memperhatikan kebutuhan jasmani antar sesama sebagai anggota tubuh Kristus yang baik. Yang mana awalnya hanya kekeluargaan sebatas suku saja, namun sekarang keluarga di dalam Kristus. Semuanya berpusat pada Kristus dan untuk

\footnotetext{
${ }^{41}$ Lotnatigor Sihombing, "ISU ETIKA SOSIAL DALAM GEREJA YANG MULA-MULA," Jurnal Amanat Agung 11, no. 1 (May 2015): 174.
} 
kemuliaan Kristus dan bukan kemuliaan pemimpin umat atau pemimpin gereja dalam suku Dayak Ngaju.

\section{KESIMPULAN}

Nilai filosofi yang terkandung di dalam Huma Betang suku Dayak Ngaju memiliki potensi membina umat percaya secara kontekstual. Filosofi Huma Betang juga merupakan nilai awal yang baik bagi masyarakat Dayak Ngaju yang dapat digunakan untuk menanamkan gaya hidup jemaat mula-mula yang sebagai teladan gereja yang sejati. Keempat pilar yang terbentuk dalam filosofi Huma Betang yaitu nilai kebersamaan, nilai kejujuran, nilai kesetaraan, dan nilai kekeluargaan secara berurutan dapat digunakan untuk menanamkan gaya hidup jemaat mula-mula yaitu persekutuan, integritas diri, kasih terhadap sesama, dan juga sebagai tubuh Kristus yang sejati. Penelitian ini dapat menjadi rujukan bagi para pelayan Tuhan yang melayani dalam suku Dayak Ngaju untuk membina umat agar memiliki gaya hidup sebagaimana jemaat mula-mula.

\section{DAFTAR PUSTAKA}

Apandie, Chris, and Endang Danial Ar. "Huma Betang: Identitas Moral Kultural Suku Dayak Ngaju Kalimantan Tengah." Journal of Moraland Civic Education Vol. 3, No. 2 (2019): 76-91.

Barclay, William. Pemahaman Alkitab Setiap Hari: Kitab Kisah Para Rasul. Jakarta: BPK Gunung Mulia, 2007.

Brink, H.v.d. Tafsiran Alkitab Kisah Para Rasul. Jakarta: BPK Gunung Mulia, 2008.
Carson, Donald A., Richard T. France, Donald Guthrie, and Douglas J. Moo. Tafsiran Alkitab Abad Ke-21 Jilid 3: Matius-Wahyu. Jakarta: Yayasan Komunikasi Bina Kasih, 2017.

Cherrington, D.J., and J.O. Cherrington. Understanding Honesty. 6th ed. Vol. 50. Internal Auditor, n.d.

D., Yoyada Chriat, Deddi Duto H., and Elisabeth Christine Y. "Perancangan Merchandise Sebagai Media Promosi Budaya Khas Dayak Ngaju Kalimantan Tengah.” Jurnal DKV Adiwarna, Universitas Kristen Petra 2, no. 13 (2018): 1-9.

Kadir, Abdul. "Konsep Pembelajaran Konseptual Di Sekolah.” Dinamika Ilmu 13, no. 1 (June 2013).

Keefauver, Larry. 77 Kebenaran Yang Hakiki Dalam Pelayanan. Semarang: Media Injil Kerajaan, n.d.

Laksono, P.M. dkk. Pergulatan Identitas Dayak Dan Indonesia: Belajar Dari Tjilik Riwut. Yogyakarta: Galangpress, 2006.

Lee, Witness. Pelajaran-Hayat Kisah Para Rasul. Yayasan Perpustakaan Injil Indonesia (Yasperin), 2020.

Lukman, Anggia Amanda. "Pewarisan Nilai Sebagai Pembentuk Kepribadian Berkarakter Melalui Falsafah Huma Betang Suku Dayak Kalimantan.” sosietas 8, no. 1 (2018): 452-456.

Marbun, Purim. "Strategi Dan Model Pembinaan Rohani Untuk Pendewasaan Iman Jemaat." Jurnal Ilmiah Religiosity Entity Humanity (JIREH) 2, no. 2 (December 23, 2020): 151-169. 
Maresty, Era, and Zamroni. "Analisis NilaiNilai Budaya Huma Betang Dalam Pembinaan Persatuan Kesatuan Bangsa SIswa SMA Di Kalimantan Tengah." Harmoni Sosial: Jurnal Pendidikan IPS 4, no. 1 (March 2017): 67-79.

Moleong, Lexy J. Metodologi Penelitian Kualitatif. Bandung: Remaja Rosdakarya, 2018.

Panggarra, Robi, and Leonard Sumule. "Pengaruh Pelayanan Pemuda Berbasis Kontekstual Terhadap Pertumbuhan Gereja Kemah Injil Indonesia Di Kota Samarinda." Jurnal Jaffray Vol. 17, No 1 (April 2019): 91-106.

Pelu, Ibnu Elmi AS, and Jefry Tarantang. "Interkoneksi Nilai-Nilai 'Huma Betang' Kalimantan Tengah Dengan Pancasila." Jurnal Studi Agama dan Masyarakat 14, no. 2 (December 2018): 119-126.

Rahmawati, Ni Nyoman. "Implementasi Nilai Keharifan Lokal (Huma Betang) Dalam Interaksi Sosial Masyarakat Dayak Di Kota Palangka Raya.” Jurnal Tampung Penyang 17, no. 1 (June 2019): 18-30.

Riwut, Tjilik. Kalimantan Membangun Alam Dan Kebudayaan. Yogyakarta: NR Publishing, 2007.

Rumbi, Frans Paillin. "Manajemen Konflik Dalam Gereja Mula-Mula: Tafsir Kisah Para Rasul 2:41-47" (n.d.). Accessed February 23, 2021. https://core.ac.uk/reader/231150420.

Sahartian, Santy. "Pengaruh Pembinaan Rohani Di Keluarga Terhadap Karakter Pemuda Berdasarkan Kolose 2:6-10.” Jurnal Teologi
Sistematika Dan Praktika Vol. 2, No 1 (June 2019): 20-39.

Scoot, Morton. Pemuridan Untuk Semua Orang. Surakarta: Literatur Perkantas, 2011.

Selan, Ruth F. Pedoman Pembinaan Jemaat. Bandung: Kalam Hidup, 2006.

Setiawan, Albi Anggito, Johan. Metodologi penelitian kualitatif. Sukabumi: CV Jejak (Jejak Publisher), 2018.

Sihombing, Lotnatigor. "ISU ETIKA SOSIAL DALAM GEREJA YANG MULA-MULA." Jurnal Amanat Agung 11, no. 1 (May 2015): 169180.

Sukarna, Sukarna. "Integritas Seorang Pendidik." JURNAL TEOLOGI GRACIA DEO 1, no. 1 (December 2018). Accessed February 23, 2021. http://ejournal.sttbaptisjkt.ac.id/index.php/gr aciadeo/article/view/18.

Suwarno, Suwarno. "Budaya Huma Betang Masyarakat Dayak Kalimantan Tengah Dalam Globalisasi: Telaah Konstruksi Sosial." LINGUA : Jurnal Bahasa, Sastra, dan Pengajarannya 14, no. 1 (January 2017): 89-102.

Tembay, Aris Elisa, and Febriaman Lalaziduhu Harefa. "Gerakan Perintisan Jemaat Dalam Kisah Para Rasul Bagi Pengembangan Gereja Masa Kini." SCRIPTA: Jurnal Teologi dan Pelayanan Kontekstual 3, no. 1 (2017): 23-47.

Tomatala, Yakob. Yesus Kristus Juruselamat Dunia. Jakarta: YT Leadership Foundations, 2004. 
West, Sandy Lane. Handbook To The Bible. Bandung: Kalam Hidup, 2015.

Whitney, Donald S. Spiritual Check Up - 10 Pertanyaan Untuk Memeriksa Kesehatan Rohani Anda. Yogyakarta: Yayasan Gloria, 2011.

Yusuf, Muhammad. Relasi Teks Dan Konteks. Yogyakarta: Indie Book Corner, 2020. 